\title{
Energy of the Gravitational Field as an Equivalent of the Dark Energy of the Universe
}

\author{
Valentyn Nastasenko \\ Kherson State Maritime Academy, Kherson, Ukraine \\ Email: nastasenko2004@ukr.net
}

How to cite this paper: Nastasenko, V. (2021) Energy of the Gravitational Field as an Equivalent of the Dark Energy of the Universe. Journal of Applied Mathematics and Physics, 9, 1541-1548. https://doi.org/10.4236/jamp.2021.97105

Received: June 15, 2021

Accepted: July 19, 2021

Published: July 22, 2021

Copyright (อ 2021 by author(s) and Scientific Research Publishing Inc. This work is licensed under the Creative Commons Attribution International License (CC BY 4.0).

http://creativecommons.org/licenses/by/4.0/

(c) (i) Open Access

\begin{abstract}
Determination of the structural foundations and parameters of the Universe is an important urgent task since it enables us to understand and explain the structure and basic parameters of the material world. Herewith, it is necessary to be aware of modern problems of physics and possible ways to solve them. Among such problems, hypotheses concerning dark matter and the energy of the Universe occupy an important place. However, the determination of their on the basis of modern theories still leads to abstract equations that do not give concrete results; therefore, they have a level of hypotheses. A number of initial scientific propositions based on this abstract of mathematical dependencies have controversial meanings. Elimination of this disadvantage is the main goal of the work performed. Its main difference and scientific novelty are the justification of the energy parameters of the gravitational field of the Universe, the magnitude of which can replace its dark energy and dark mass. The solution to this problem is justified by strict physical dependencies, which are obtained on the basis of fundamental physical constants. It is an urgent and important scientific and applied problem, since it develops knowledge about the gravitational field and the material world in general. The performed work is based on the methods of deduction and induction in the research of the material world based on the application of the well-known reliable laws of physics and the general principles of the development of the theory of knowledge. Other research methods are still unknown, since the work performed is associated with new scientific discoveries, the search for which is difficult to formalize by technique methods. The results of the study consist of the analysis of wave, force and energy parameters of the relict gravitational field of the Universe. The calculated value of this energy is $1.58 \times 10^{70} \mathrm{~J}$. This energy is enough to cover the amount of dark energy and mass in the Universe, which casts doubt on their existence. Conclusions: This paper can supplement previously performed research on the dark mass and energy of the Universe, which requires further for their reconciliation.
\end{abstract}




\section{Keywords}

Wave, Force and Energy Parameters of the Relict Gravitational Field of the Universe and the Possibility of Replacing of Them Dark Energy and Mass

\section{Introduction}

Determination of the structural foundations and parameters of the Universe is an important urgent task since it enables us to understand and explain the structure and basic parameters of the material world. Herewith, it is necessary to be aware of modern problems of physics and possible ways to solve them. Among such problems, hypotheses concerning dark matter and the energy of the Universe occupy an important place. This work is devoted to the analysis of these hypotheses and the possibility of their explanation.

\section{The Choice of the Goal and Objectives of the Work}

Currently, dark energy is one of the mysteries of the Universe, which is given special attention in a large number of scientific works [1]. The creation of powerful ground-based, and especially orbiting telescopes operating in various wavelengths, has made it possible to obtain results that confirm the theoretical data accumulated in this field. In recognition of the importance of these works, the 2019 Nobel Prize in Physics was awarded to James Peebles "for theoretical discoveries in the field of physical cosmology" [2]. In his works, he calculated the spectrum of the relict radiation fluctuations, adding to his model ordinary matter with the cold dark matter as well as dark energy with negative density [2]. On their basis, with an accuracy of $\approx 0.1 \%$, it was obtained that the total energy of the observed Universe consists of $69 \%$ of dark energy, $26 \%$ of dark matter, and only $5 \%$ of ordinary baryonic matter.

However, new observations of distant galaxies contradict this understanding of the nature of dark matter and dark energy [3]. An unexpected discrepancy was revealed between observations of the concentration of dark matter in three massive clusters of galaxies, including trillions of stars in his, and theoretical computer models of how dark matter should be distributed [3]. According to the leading astrophysicist of Yale University Priyamvada Natarajani, "either a component was missing in the modeling, or we made a fundamentally incorrect assumption about the nature of dark matter" [3], which requires analysis and development of previously performed research. A more complete criticism of the parameters of dark energy and dark mass is presented in [4].

In view with the above, the works [5] [6], in which the energy indicators of the gravitational field were determined, are of certain interest. The advantage of these works is that, in contrast to dark energy with negative density (the parameters of which do not have explicit physical models and are determined theoretically on the basis of mathematical dependencies), the parameters of the gra- 
vitational field are obtained on the basis of explicit physical models and strict dependencies [7] [8] [9]. They flow out from reliable physical laws and regularities associated with fundamental physical constants.

Determination of the forces and energy parameters of the gravitational field on the basis of reliable physical laws is the main goal of the work performed.

The second goal of the work is the introduction of modern information about the gravitational field, its power and energy parameters in the new scientific research.

\section{Working Methods}

This work is based on the methods of deduction and induction in the study of the material world based on the application of well-known reliable laws of physics and general principles of development theory of knowledge. Other methods were not used, since this work is associated with scientific discoveries, for the creation of which strict algorithmic methods have not yet been developed.

\section{Results and Their Discussion}

The possibility of achieving the goals set is justified by the new scientific knowledge obtained in recent years in the field of studying the gravitational field:

1) the discovery of gravitational waves and the processes of their formation in the Universe, which was awarded the Nobel Prize in Physics in 2017 [10], herewith, the values of their wave parameters were not determined.

2) the rigorous substantiation of the wave parameters of the gravitational field and their values [7] [8] [9], however, they are still little known in the scientific world.

3) the substantiation of the possibility of replacing dark energy and mass with the energy parameters of the gravitational field [4], which is also still little known in the scientific world.

It should be noted that the works of the Nobel laureates are widely covered in scientific and popular-scientific literature, which allows them to be used in new scientific research. At the same time, a large number of scientific works are devoted to solving the problems of determining the parameters of the gravitational field, among which a number of publications can be distinguished [11] [12] [13] [14] since their references to previously completed works form a coherent picture of the level of scientific achievements obtained on their basis. However, the principle of generalization used in them on the basis of the development of previously known and the creation of new mathematical theories significantly complicates the problem of obtaining final results for which the numerical values have not been determined.

Insufficient popularity of works [4]-[9], published in editions with little scientific authority, reduces attention to them and the further level of development of science and training of scientists. However, their value lies in the application of an unconventional approach to solving such problems based on the transition to 
the zero level of the material world [15], which precedes the level of elementary particles and atoms. Herewith, the search for the required solutions is simplified, and the possibility of obtaining the final specific scientific result, in particular, in the form of its numerical values is provided. Therefore, elimination of the indicated drawback is required.

The main distinctive feature and scientific novelty of the work performed is the substantiation of the strength and energy of the gravitational field of the Universe on the basis of a strict definition of its wave parameters and their numerical values.

The found values of the energy and energy mass of the gravitational field can be further used to compare them with the dark energy and dark mass of the Universe in future scientific research. Thus, the data obtained are of great interest to researchers working in this field.

Frequency $v_{G}$ of the gravitational field is determined by strict physical dependence (1) [7] [8] [9] is Nastasenko's quantum frequency constant:

$$
v_{G}=v_{p}=\sqrt{\frac{c^{5}}{G h}}=7.39994 \times 10^{42}\left(\mathrm{~s}^{-1}\right) \rightarrow 7.4 \times 10^{42}\left(\mathrm{~s}^{-1}\right) .
$$

where: $G$, gravitational constant recommended by CODATA [16]:

$$
G=6.67408(31) \times 10^{-11}\left(\frac{\mathrm{m}^{3}}{\mathrm{~kg} \cdot \mathrm{s}^{2}}\right) .
$$

$\mathcal{C}$, speed of light in vacuum [16]:

$$
c=0.299792458 \times 10^{9}\left(\frac{\mathrm{m}}{\mathrm{s}}\right)
$$

$h$, Planck's constant [16]:

$$
h=6.626070040 \times 10^{-34}(\mathrm{~J} \cdot \mathrm{s})=6.626070040 \times 10^{-34}\left(\frac{\mathrm{kg} \cdot \mathrm{m}^{2}}{\mathrm{~s}}\right) .
$$

On the basis frequency of the gravitational field $v_{G}$ in [8] [9] which made it possible to obtain its other wave parameters the gravitational fields at the strict physical level:

Period of oscillation $T_{G}(\mathrm{~s})$ :

$$
T_{G}=\frac{1}{v_{G}}=\frac{1}{7.4 \times 10^{42}\left(\mathrm{~s}^{-1}\right)}=0 .|135| \times 10^{-42}(\mathrm{~s}),
$$

Length of carrier wave $\lambda_{\mathrm{G}},(\mathrm{m})$

$$
\lambda_{G}=\frac{c}{v_{G}}=4.051249|432| \times 10^{-35}(\mathrm{~m}),
$$

Amplitude of oscillation $A_{G}(\mathrm{~m})$ :

$$
A_{G}=\lambda_{G}=4.051249|432| \times 10^{-35}(\mathrm{~m}) .
$$

Wave energy $E_{G}$, its maximum quantum of energy $(\mathrm{J})$ :

$$
E_{G}=h v_{G}=4.9032918286 \times 10^{9}(\mathrm{~J})=E_{p}=\sqrt{\frac{h c^{5}}{G}}=4.90326 \times 10^{9}(\mathrm{~J}) .
$$


Mass equivalent $m_{G}$ of the wave energy $E_{G}$ of the gravitational field, or its energy mass, which in the framework of law: Plank's energy $E_{G}=h v_{G}$ and Einstein's on connection of total energy and mass $E_{G}=m_{G} C^{2}$, its maximum quantum of mass:

$$
m_{G}=\frac{E_{G}}{c^{2}}=\frac{h v_{G}}{c^{2}}=5.455647929 \times 10^{-8}(\mathrm{~kg}) .
$$

This parameter (5), (6), (7), (8), (9) obtained on the basis of strict physical regularities, consisting of 3 initial fundamental physical constants (2), (3), (4) [8] [9].

To determine the force of the gravitational field used of force $F_{G}(10)$ of Newton's law of gravitation is base [17]:

$$
F_{G}=G \frac{m_{1} m_{2}}{r^{2}}(\mathrm{~N}) \text {. }
$$

where: $m_{1}, m_{2}$, mass of 2-point 1 bodies and the distance $r$ between them:

Herewith, the total mass $m_{l}$ of waves of the gravitational field is replaced by its equivalent on the energy mass $m_{G}(11)$ :

$$
m_{1}=N_{G} m_{G}=N_{G} \frac{h v_{G}}{c^{2}}(\mathrm{~kg}) .
$$

where $N_{G}$ is the number of wavelengths $\lambda_{G}$ at a distance $r$ to any object having a mass $m_{2}$ :

$$
N_{G}=\frac{r}{\lambda_{G}} .
$$

The obtained values (11), (12) allow us to find a new strict physical dependence for the force $F_{G}$ :

$$
F_{G}=G \frac{m_{1} m_{2}}{r^{2}}=G \frac{N_{G} h v_{G} m_{2}}{r^{2} c^{2}}=G \frac{r h v_{G} m_{2}}{\lambda_{G} c^{2} r^{2}}=G \frac{h v_{G} m_{2}}{\lambda_{G} c^{2} r}=\frac{G h v_{G}}{\lambda_{G} c^{2}} \cdot \frac{m_{2}}{r}(\mathrm{~N}) .
$$

Since the constants $G, h, c, v_{G}, \lambda_{G}$ within the framework of their dimensions [5] [6] [7] [8] [9] can be expressed in terms of the Planck's values: length $I_{p}$, time $t_{p}$, mass $m_{p}$, [18] we obtain strict physical dimension:

$$
\frac{G h v_{G}}{\lambda_{G} c^{2}}=\frac{\left(\frac{l_{p}^{3}}{m_{p} t_{p}^{2}}\right) \cdot\left(\frac{m_{p} l_{p}^{2}}{t_{p}}\right) \cdot\left(\frac{1}{t_{p}}\right)}{\left(l_{p}\right) \cdot\left(\frac{l_{p}}{t_{p}}\right)^{2}}=\left(\frac{l_{p}}{t_{p}}\right)^{2}=c^{2} .
$$

Used (14) and taking into account the value (15), we finally get a strict physical dependence for calculating the force $F_{G}$ [5] [6]:

$$
F_{G}=c^{2} \frac{m_{2}}{r}=\frac{m_{2} c^{2}}{r}(\mathrm{~N}) \text {. }
$$

This dependence (15) implies that the force $F_{G}$ of the gravitational field action on an object of mass $m_{2}$ is energetical. It is directly proportional to the total energy $m_{2} c^{2}$ of the selected body and inversely proportional to the distance $r$ 
between it and any selected base of the gravitational field. These results were presented at international conferences [19] [20] [21].

Further studies showed that the coefficient $K$ should be introduced into dependence (15), which takes into account the size-mass characteristics of gravitational objects:

$$
F_{G}=K \frac{m_{2} c^{2}}{r}(\mathrm{~N}) .
$$

The energy parameters of this gravitational field, which should be considered "relict" for the Universe, are the value $E_{G}=h v_{G}(8)$ per 1 layer of spherical waves. It has a length of $4.05 \times 10^{-35} \mathrm{~m}$ in the transverse direction, the oscillation period is $T_{G}(5)$, and along these spheres they cover the entire space of the Universe in layers. With its age $T_{U}=13.8$ billion years [22], the length of the year is 365 days, in which $86,400 \mathrm{~s}$, the value of this energy will be:

$$
\sum E_{G}=E_{G} \frac{T_{U}}{T_{G}}=4.9 \times 10^{9}(\mathrm{~J}) \frac{13.8 \times 10^{9} \times 365 \times 86400(\mathrm{~s})}{0.135 \times 10^{-42}(\mathrm{~s})}=1.58 \times 10^{70}(\mathrm{~J})
$$

This energy is enough to cover the amount of dark energy and mass in the Universe, which casts doubt on their existence. This is explained by the fact that with an average density of matter in the Universe between $\rho_{U}=5 \times 10^{-27}$ and $3 \times$ $10^{-28} \mathrm{~kg} / \mathrm{m}^{3}$ [23], which has an age of $T_{U}=13.8$ billion years, what limits its cosmological horizon with a radius $R_{U}(18)$, the total mass of matter contained within this volume is $M_{U}=(19)$ :

$$
\begin{aligned}
R_{U}= & T_{U} c_{G}=13.8 \times 10^{9} \times 365 \times 86400(\mathrm{~s}) \times 0.29979 \times 10^{9}\left(\frac{\mathrm{m}}{\mathrm{s}}\right) \\
= & 1.30 \times 10^{26}(\mathrm{~m}) \\
M_{U}= & \rho_{U} \frac{4}{3} \pi R_{U}^{3}=\left[5 \times 10^{-27} \ldots 3 \times 10^{-28}\left(\frac{\mathrm{kg}}{\mathrm{m}^{3}}\right)\right] \frac{4}{3} \pi \times\left[1.30 \times 10^{26}(\mathrm{~m})\right]^{3} \\
= & 4.60 \times 10^{52} \ldots 2.76 \times 10^{51}(\mathrm{~kg})
\end{aligned}
$$

The energy equivalent of this mass $E_{m}=m c^{2}$ is:

$$
\begin{aligned}
E_{m} & =4.60 \times 10^{52} \ldots 2.76 \times 10^{51}(\mathrm{~kg}) \times\left[0.29979 \times 10^{9}\left(\frac{\mathrm{m}}{\mathrm{s}}\right)\right]^{2} \\
& =0.41 \times 10^{70} \ldots 0.025 \times 10^{70}(\mathrm{~J})
\end{aligned}
$$

The ratio of the energy of matter (20) to the energy of the gravitational field (17) in \% is the value (21):

$$
\frac{E_{m}}{E_{G}} \times 100 \%=\frac{0.41 \times 10^{70} \ldots 0.025 \times 10^{70}(\mathrm{~J})}{1.58 \times 10^{70}(\mathrm{~J})} \times 100 \%=26 \ldots 1.6 \%
$$

This range includes a $4.5 \%$ energy fraction of substance [2], which is acceptable for the initial density determination accuracy $\rho_{U}=5 \times 10^{-27}$ and $3 \times 10^{-28}$ $\mathrm{kg} / \mathrm{m}^{3}$.

The found values of the energy and energy mass of the gravitational field (17) can be further used to compare them with the dark energy and dark mass of the 
Universe (20) in future scientific research. Thus, the data obtained are of great interest to researchers working in this field.

\section{Conclusions}

1) This paper does not deny the previously performed research on the dark mass and energy of the Universe; however, it can supplement them, which requires further research for their reconciliation.

2) New data on the energy of the gravitational field and its energy mass were obtained on the basis of strict physical laws, which confirm their reliability, therefore, all research in this area without taking into account the found parameters will be incomplete, and the works will remain unaccomplished.

3) The results obtained have the level of scientific discoveries that contribute to the development of science; which should be taken into account when conducting further research on their basis.

\section{Section of Acknowledgments}

Materials of works of other authors and organizations were not used.

\section{Conflicts of Interest}

The author declares no conflicts of interest regarding the publication of this paper.

\section{References}

[1] Vyblyy, Y.U.P. and Leonovich, A.A. (2020) Kosmologiya i astrofizika-Peredniy kray fundamental'noy nauki [Cosmology and Astrophysics-The Cutting Edge of Fundamental Science]. Institut fiziki NAN Belarusi, Minsk. (In Russian) https://ibeldoc.bsuir.by/bitstream/123456789/38597/1/Vyblyy Kosmologiya.pdf

[2] Nobel Prize in Physics (2019). https://nplus1.ru/news/2019/10/08/nobel-physics-2019

[3] (2020) Uchenyye sbity s tolku novymi otkrytiyami zagadochnoy temnoy materii [Scientists Are Baffled by New Discoveries of the Mysterious Dark Matter]. http://kontrakty.ua/article/162364

[4] Nastasenko, V. (2020) Energy of the Gravitational Field as an Equivalent of the Dark Energy of the Universe. In: Abstracts of the 2 nd International Scientific and Practical Conference, CPN Publishing Group, Kyoto, 76-83.

https://sci-conf.com.ua/ii-mezhdunarodnaya-nauchno-prakticheskaya-konferentsiy a-science-and-education-problems-prospects-and-innovations-4-6-noyabrya-2020goda-kioto-yaponiya-arhiv

[5] Nastasenko, V.A. (2017) Strogoye obosnovaniye sily deystviya gravitatsionnogo polya. Naukoviy vísnik KHDMA: Naukoviy zhurnal. Kherson: KHDMA, 2, 170-180. (In Russian)

[6] Nastasenko, V. (2019) Refinement of Law the World Gravitation Force for Gravitational Field of the Universe. Journal of Astrophysics and Aerospace Technology, 7, 42.

[7] Nastasenko, V.A. (2013) O vozmozhnosti utochneniya znacheniya gravitatsionnoy postoyannoy raschetnym putem [On the Possibility of an Clarification Value of the Gravitational Constant by Calculation]. In: Materialy Mezhdunar. nauch.-tekhn. 
konf. Vysokoproizvoditel nyye vychislitel nyye sistemy, NUTU KPI, Kiyev, 266-272. (In Russian)

[8] Nastasenko, V.A. (2014) O vozmozhnosty opredelenyya volnovykh parametrov hravytatsyonnoho polya [On the Possibility of Determining the Wave Parameters of a Gravitational Field]. In: Visnyk Khersons' koho natsionaP noho tekhnichnoho universytetu, KHNTU Vyp, Kherson, Vol. 1, 71-76. (In Russian)

[9] Nastasenko, V.A. (2018) Discovery of Analytical Method Defined of Wave Parameters Gravitation Field. International Conference on Quantum Physics, Optics and Laser Technologies, Tokyo, 9-10 May 2018, 1 p.

https://www.hilarispublisher.com/proceedings/discovery-of-analytical-method-defi ned-of-wave-parameters-gravitation-field-20259.html

[10] Nobel Prize (2017). https://www.nobelprize.org https://www.nobelprize.org/nobel prizes/physics/laureates/2017/press.htmc

[11] Eynshteyn, A. and Gravitatsii, T. (1979) Albert Einstein and the Theory of Gravity. Mir, Moscow. (In Russian)

[12] Charl'z, M., Kip, T. and Dzhon, U. (1977) Gravitatsiya [Gravitation]. Mir, Moscow, T.1. (In Russian)

[13] Landau, L.D. and Lifshits, Ye.M. (1988) Teoriya Polya. [The Classical Theory of Fields]. Nauka, Moscow, izd. 7, 512 S. (In Russian)

[14] Morozov, V.B. (2021) On Gravity Field Equation. Electronic Resource. https://www.researchgate.net/publication/344331332 On gravity field equation

[15] Nastasenko, V. (2021) Selection and Justification of a New Initial Level of the Material World. Journal of Applied Mathematics and Physics, 9, 1089-1099. https://doi.org/10.4236/jamp.2021.95075

[16] CODATA Internationally Recommended Values of the Fundamental Physical Constants. https://physics.nist.gov/cuu/Constants/index.html

[17] Alekseev, D.V., Bonch-Bruevich, A.M., Voronov-Romanov, A.S., et al. (1983) Phizicheskij encyclopedicheskij slovar [Physical Encyclopaedic Dictionary]. Soviet Encyclopedia, Moscow. (In Russian)

[18] Belov, A.F. and Voskobounikov, V.G. (1989) Polytechnic Dictionary. 3rd Edition, Soviet Encyclopedia, Moscow, 134, 382, 486, 638-640. (In Russian)

[19] Nastasenko, V.A. (2018) Strict Justification of the Force of the Gravitational Field. Theoretical, Materials and Condensed Matter Physics 5 th International Conference, Los Angeles, 26-28 November 2018, Volume 6, 64.

https://www.rroij.com/proceedings/strict-justification-of-the-force-of-the-gravitatio nal-field-810.html

[20] Nastasenko, V.A. (2018) The Presentation of the Law of Universal Gravitation for Gravitational Field. 6th International Conference on Quantum Physics, London, 5-6 November 2018, 22.

[21] Nastasenko, V. (2019) Refinement of Law the World Gravitation Force for Gravitational Field of the Universe. Journal of Astrophysics \& Aerospace Technology, No. 7,42 .

[22] https://www.google.com.ua/search?q=\%D0\%B2\%D0\%BE\%D0\%B7\%D1\%80\%D0\% B0\%D1\%81\%D1\%82+\%D0\%B2\%D1\%81\%D0\%B5\%D0\%BB\%D0\%B5\%D0\%BD\%D 0\%BD\%D0\%BE\%D0\%B9\&sxsrf=ALeKk01k0fgT4lmKj3OgcNk4veZZVMogKw\%3A 1623721914861\&source

[23] https://cyberlesson.ru/massa-vselennoj-v-kilogrammah/\#obsij-razmer-i-massa-vsel ennoj 